\title{
Clinical Studies of Rheocardiography Application to Hemodynamic Monitoring of Patients with Dilated Cardiomyopathy
}

\author{
B. Przywara-Chowaniec ${ }^{a}$, L. Poloński $^{b}$, M. Gawlikowski $^{c}$ and T. Pustelny ${ }^{c, *}$ \\ ${ }^{a}$ II Department and Clinic of Cardiology, Silesian Medical Univ., M. Skłodowskiej-Curie 10, 41-800 Zabrze, Poland \\ ${ }^{b}$ III Department and Clinic of Cardiology, Silesian Medical Univ., Szpitalna 2, 41-800 Zabrze, Poland \\ ${ }^{c}$ Department of Optoelectronics at Silesian University of Technology, Akademicka 2, 44-100 Gliwice, Poland
}

\begin{abstract}
Impedance cardiography is a non-invasive, cheap and easy to use method of long term hemodynamic monitoring. Nowadays this method is perceived as an alternative for invasive monitoring of the patients. The goal of the presented papers was to compare the results of rheocardiography with reference invasive monitoring.
\end{abstract}

PACS numbers: 47.63.Cb, 87.19.U-

\section{Introduction}

The progress in medical physics and technical science has contributed to the development of new, low invasive methods of hemodynamic monitoring of the patients. Among a few, non-invasive methods (2D and 3D echocardiography [1], the pulse-contour method [2], photoelectric analysis of respiratory gases [3]) impedance rheocardiography is of special importance. The basis of this method is the measurement of electric impedance variations the alternating electric current $(20-100 \mathrm{kHz}$, typically $83 \mathrm{kHz}$ ) is provided to investigated region of body and the voltage drop is measured. The pulsatile flow through the vessels (especially of a large-diameter, like the aorta) causes impedance variations $\Delta Z$ and the first derivative of this function correlates with the maximum flow in the ascending aorta. The mathematical model of this phenomenon was proposed by Kubicek et al. [4-6]. The pick flow $(\mathrm{PF})$ in the ascending aorta is given by Eq. (1):

$$
\mathrm{PF}=\frac{\rho L^{2}}{Z_{0}^{2}}\left(\frac{\mathrm{d} Z}{\mathrm{~d} t}\right)_{\max }[\mathrm{ml} / \mathrm{s}],
$$

where $\rho$ - specific resistance of blood, $L$ - distance between the electrodes, $Z_{0}$ - base impedance.

The base impedance $Z_{0}$ is a total impedance of the thorax and it may indicate the intra-thoracic liquid [7]. The stroke volume (SV) of the left ventricle can be calculated by multipling $\mathrm{PF}$ by the ventricle eject time (VET):

$$
\mathrm{SV}=\mathrm{PF} \cdot \mathrm{VET} \text {. }
$$

The accurate estimation of the specific resistance of blood is necessary to decrease unreliability of the method. However, several authors have reported that for a wide range of haematocrit $(\mathrm{HCT}=22-66 \%)$ the $\rho$ parameter is constant and equals $135 \Omega \mathrm{cm}[8]$.
In spite of a significant progress in impedance cardiography, the pulmonary artery catheterization (PAC) and the thermal dilution cardiac output measurement remains a gold clinical standard in hemodynamic diagnostics [9].

\section{Goal}

Despite of non-invasiveness, the low cost and easiness of application impedance cardiography is not a popularized examination in clinical practice. It involves some small verification of the method on patients. The constant development of technical realizations of the method and required apparatus inclined the authors to undertake the problem of assessing the usability of impedance cardiography in hemodynamic monitoring in the clinic.

The goal of the work was to compare selected hemodynamic parameters measured rheocardiographically with invasive pulmonary artery catheterization (reference).

\section{Material and methods}

\subsection{Material}

The investigations were performed on 22 patients $(6 \mathrm{~F}$, $16 \mathrm{M}$, age $42 \pm 4.1$ ) treated for circulatory insufficiency in the course of dilated cardiomyopathy during preliminary diagnostics before heart transplantation [10]. Patients with chronic aortic valve disease were excluded. On the day of admission, by isotope radiography the ejection fraction $(\mathrm{EF})$ was examined $(\mathrm{EF}=10 \% \ldots 35 \%)$. The details of the population's division by functional classification NYHA have been presented in Table. All patients were treated in the 2nd Clinic of Cardiology at the Silesian Medical University in Zabrze.

\footnotetext{
* corresponding author; e-mail: tadeusz.pustelny@polsl.pl
} 
TABLE

The functional classification of the patients.

\begin{tabular}{c|c|c}
\hline \hline & NYHA III & NYHA IV \\
\hline Number of patients & 4 & 18
\end{tabular}

\subsection{Methods}

The examinations were started at 10 am, after $30 \mathrm{~min}$ rest, during rhythmical respiration. The examination scheme was as follows:

1. invasive monitoring,

2. $5 \mathrm{~min}$ long rheocardiogram registration,

The body surface area (BSA) ratio was calculated in compliance with the DuBois formula. Details of the examination procedures have been described below.

\subsubsection{Impedance cardiography}

The AVL2001HDM (AVL LIST GmbH) monitor was utilized. Four pairs of electrodes were located on the body (see Fig. 1):

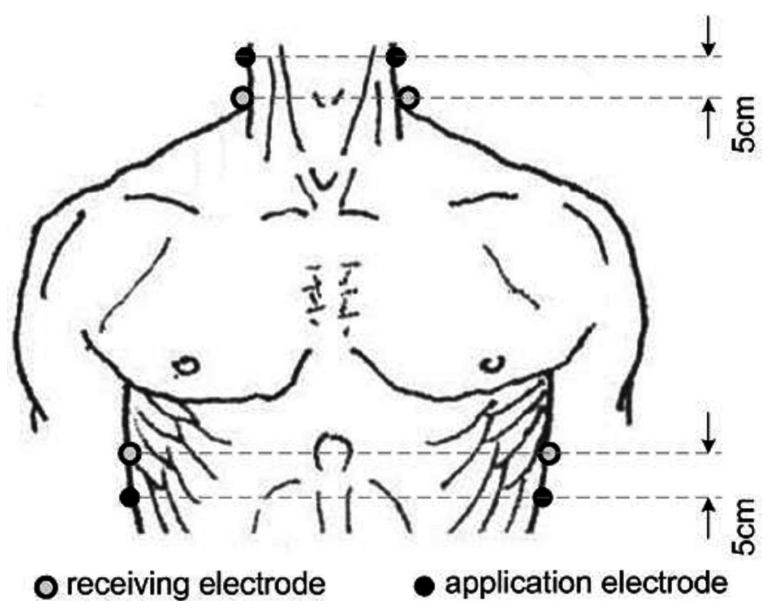

Fig. 1. Location of the electrodes in impedance cardiography examination.

- the first pair of receiving electrodes was located aside the base of the neck,

- the second pair of receiving electrodes was located perpendicularly to the longitudinal axis of the sternum, laterally from the xiphoid process in a midaxillary line,

- application electrodes were located parallel to the receiving one, $5 \mathrm{~cm}$ above the upper and $5 \mathrm{~cm}$ below the lower receiving electrodes.

The following hemodynamic parameters were recorded: cardiac index (CI), stroke volume index (SI), ejection fraction (EF), end diastolic volume index (EDVI), systemic vascular resistance index (SVRI), thoracic fluid conductance (TFC) and mean arterial pressure (MAP).

\subsubsection{Invasive monitoring}

The invasive hemodynamic monitoring was performed by the Swan-Ganz catheter (7F size), inserted at the pulmonary arterial trunk through the left or right subclavian vein. For cardiac output $(\mathrm{CO})$ measurements of the thermal dilution method at room temperature were applied. $0.9 \% \mathrm{NaCl}$ solution was used as an indicator. The volume of the bolus was $10 \mathrm{ml}$. During every examination at least three measurements were taken. Hemodynamic calculations were performed by 4510A American Edwards Lab. apparatus. Parallel to CO monitoring, the following pressures were measured: systolic and diastolic pulmonary artery pressure (PAPS, PAPD), mean pulmonary artery pressure (PAP).

\section{Results}

Because of their practical significance, as the most appropriate for further analysis the CI and SI were chosen.

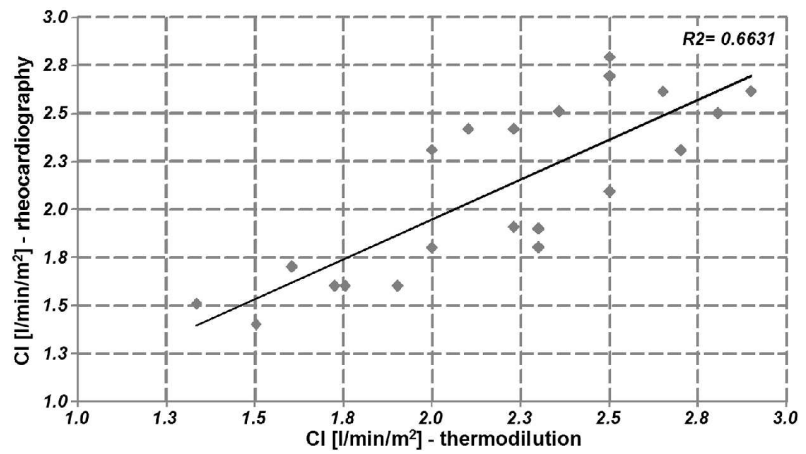

Fig. 2. The statistics of the CI (thermodilution vs. rheocardiography).

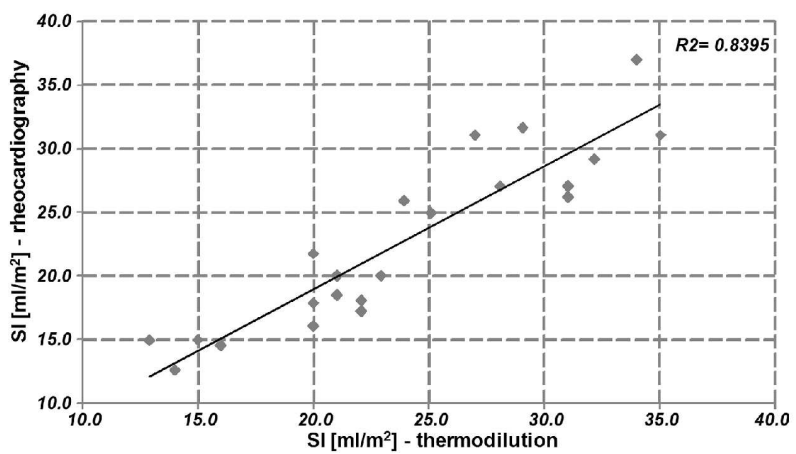

Fig. 3. The statistics of the SI (thermodilution vs. rheocardiography).

The CI comparison of thermodilution (reference) and rheocardiography was depicted in Fig. 2. The mean values of CI were: $2.20 \pm 0.4 \mathrm{l} / \mathrm{min} / \mathrm{m}^{2}$ and 
$2.0 \pm 0.4 \mathrm{l} / \mathrm{min} / \mathrm{m}^{2}$, respectively. The regression coefficient $r=0.83$ and Pearson's correlation coefficient $r^{2}=0.6631$.

The SI comparison of thermodilution (reference) and rheocardiography was depicted in Fig. 3. Mean values of SI were: $22.58 \pm 7 \mathrm{ml} / \mathrm{m}^{2}$ and $23.74 \pm 6.4 \mathrm{ml} / \mathrm{m}^{2}$, respectively. The regression coefficient $r=0.96$ and Pearson's correlation coefficient $r^{2}=0.8395$.

\section{Discussion}

Many authors [11-16] pointed out a good accuracy of impedance cardiography but in a selected group of patients only. Especially, the good correlation was observed in the case of patients with proper cardiac output. A too low or too high $\mathrm{CO}$ value significantly increased the unreliability of this method. The authors claimed that additional limitations of rheocardiography are: cardiac insufficiency, valvular incompetence, cardiac shunts and hypertension.

In the presented work, SI measurements rendered a good correlation $\left(r^{2} \approx 0.84\right)$, despite of the observed coexisting recoil wave through the mitral valve (at $44 \%$ of the examined patients measured by the Doppler echocardiography on $27 \%$ of left the atrium area). Moreover, the examinations concerned patients with a serious cardiac injury. The unreliability of rheocardiography in reference to thermodilution was $\pm 10 \%$ in a single SI measurement and its constant tendency during the treatment was observed. For that reason impedance cardiography seems to be more appropriate in the case of long term monitoring than in absolute measurements.

For CI measurements the correlation was worse than in the case of SI $\left(r^{2} \approx 0.66\right)$. Probably the reason of this should be sought in the variability of the thorax resistance and its transverse section. The investigations performed by other authors $[17,18]$ indicate that better results may be obtained for direct thorax volume estimation than by mathematical formulae (modified Sramk equation or Sramk-Bernstein equation). Moreover, the authors indicate a larger discrepancy of data concerning females than males.

\section{Conclusions}

The impedance cardiography is a non-invasive, rather cheap easily applied method of hemodynamic monitoring. In the examined population of patients with serious cardiac injury the results of CI and SI measurements by impedance cardiography distinctly correlated with reference thermodilution.

Because of metrological properties (accuracy, repeatability) rheocardiography seems to be more appropriate in long-term monitoring of the therapy progress than in absolute measurements of the hemodynamic parameters.

\section{References}

[1] W. Rydlewska-Sadowska, Clinical Echocardiography, Institute of Cardiology, Warsaw 1991 (in Polish).

[2] O. Godie, L. Friedl, A. Hannekum, Med. Sci. Moinit 6, 7, 1344 (2001).

[3] P. Peyton, B. Thompson, Journal Clinical Monitoring Computing 18, 373 (2004).

[4] G.W. Kubicek, N.J. Karnegis, P. Patterson, Aerospace Med. 37, 1208 (1966).

[5] D.P. Bernstein, Crit. Care Med. 14, 904 (1986).

[6] R.B. Pickett, C. Buell, Am. J. Cardiol. 69, 1354 (1992).

[7] M. Piechota, Folia Cardiol. 12, 1 (2005) (in Polish).

[8] W.A.F. Quail, M.W. Traugott, L. Porges, J. Appl. Physiol. 12, 51 (1981).

[9] N.S. Nieminen, Polish Cardiology 63, 2 (2005).

[10] B. Puzio, PhD. Thesis, Silesian Medical University, Zabrze 1993 (in Polish).

[11] B. Balestra, R. Malacrida, L. Leonardi, Crit. Care Med. 20, 62 (1992).

[12] J. Mehlsen, J. Bode, C. Stadeager, Clin. Physiol. 11, 579 (1991).

[13] M. Darlak, Z. Opilski, M. Gawlikowski, R. Kustosz, T. Pustelny, Artificial Organs 31, A50 (2007).

[14] T. Pustelny, P. Struk, Z. Nawrót, M. Gawlikowski, Europ. Phys. J. - Special Topics 154, 161 (2008).

[15] M. Gawlikowski, T. Pustelny, B. Przywara-Chowaniec, P. Struk, Acta Phys. Pol. A 114, A-79 (2008).

[16] T. Pustelny, P. Struk, Z. Nawrat, M. Gawlikowski, Europ. Phys. J. - Special Topics 154, 165 (2008).

[17] J.C. Miller, S.M. Horvath, Psychophysiology 15, 80 (1987).

[18] K.C. Huang, M. Stoddard, K. Tsueda, Crit. Care Med. 18, 1274 (1990). 